Article

\title{
Close-To-Nature Heuristic Design Principles for Future Urban Green Infrastructure
}

\author{
Saruhan Mosler * and Peter Hobson \\ School for Sustainable Environments \& Design, Writtle University College, UK; \\ E-Mails: saruhan.mosler@writtle.ac.uk (S.M.), peter.hobson@writtle.ac.uk (P.H.) \\ * Corresponding author
}

Submitted: 29 April 2021 | Accepted: 16 July 2021 | Published: 14 October 2021

\begin{abstract}
The global nature-climate crisis along with a fundamental shift in world population towards cities and towns has sharpened the focus on the role of urban green infrastructure. Green infrastructure has the potential to deliver cost-effective, naturebased solutions to help mitigate problems of climate change as well as provide improved human well-being through the ecosystem services inherent in landscapes rich in biodiversity. The absence of under-pinning science, specifically complex systems science and ecosystem theory in the design and planning of urban green infrastructure, has limited the capacity of these landscapes to deliver ecosystem services and to effectively demonstrate natural resilience to the impacts of climate change. To meet future challenges of environmental uncertainty and social change, the design of urban green space should embrace an adaptive ecosystem-based approach that includes fully integrated participatory planning and implementation strategies founded on principles of close to nature science. Our article offers two models to inform green space planning: urban green space framework and sustainable urban community network. Both concepts provide the foundation for six ecosystem-based design principles. In a case study on Essex green infrastructure, UK, recommendations made by the Essex Climate Action Commission to transform land management practices are presented as examples of adopting principles of the ecosystem approach and nature-based science. Our article concludes by emphasising the importance of reconnecting society with nature in cities through close-to-nature design of urban green space to secure essential ecosystem services and to build resilience to the impacts of climate change.
\end{abstract}

\section{Keywords}

ecosystem-based approach; Essex Climate Action Plan; nature-based solutions; sustainable urban community network; urban green infrastructure; urban green space framework

\section{Issue}

This article is part of the issue "Towards Green(er) Cities: Contextualizing Green Benefits for Urban Spaces and Contemporary Societies" edited by Juaneé Cilliers (University of Technology Sydney, Australia).

(C) 2021 by the authors; licensee Cogitatio (Lisbon, Portugal). This article is licensed under a Creative Commons Attribution 4.0 International License (CC BY).

\section{Introduction}

The state of the planet and the emerging impacts of climate change and biodiversity loss are in the top five global risks by "likelihood" and "impact" according to the latest Global Risks Perception Surveys (see World Economic Forum, 2019, 2020, 2021). Failure of effective socio-environmental policy coupled with increasing human development and commercial prosperity have come at a considerable cost to biodiversity as the stock of natural capital per person has declined by nearly $40 \%$, and extinction rates are estimated to be 100 to 1,000 times higher than the baseline rate (Dasgupta, 2021). Environmental trends broadly correspond with human demographic changes including a profound shift across the world towards urbanisation (Department of Economic and Social Affairs, 2018).

Across Europe, $74 \%$ of people are living in towns and cities that have had to adapt to rapid development and overcrowding by the hasty construction of often poorly 
planned new build with inherent environmental problems (Artmann et al., 2017; Bertram \& Rehdanz, 2015; Kabisch et al., 2016). Modern functional urban planning across the world operates to a "line and grid" system (Stanislawski, 1946), which includes calculating the proximity and size of open space to residential builds (Moseley et al., 2013; Natural England, 2010). Experts argue that such linear green island models ignore more complex site specific and social factors such as mobility and the distance people are prepared to travel from their homes to communal green spaces (Grahn \& Stigsdotter, 2003; Moseley et al., 2013). There has been little scope for integrating much needed green infrastructure into existing urban build (Kasanko et al., 2006), with consequences for towns and cities that require adaptive capacity and resilience to cope with rapid environmental change, such as drought and floods (Koomen \& Diogo, 2015).

A more comprehensive systematic analysis of urban open space and green infrastructure of the kind required in the assessment of ecosystem services is needed with a follow-up in appropriate adaptive management planning. In this article, we explore some of the apparent obstacles faced by urban designers and planners to working with an ecosystem services framework and propose mechanisms of knowledge transfer, using appropriate conceptual models such as regenerative design and ecosystembased design as heuristic design principles, which are structured around theories of science. Using principles of complex systems, ecological thermodynamics, and ecosystem theory, a whole system approach to urban design and planning is advanced. The article presents a contemporary case study in Essex, UK, based on the recommendations set out by the Essex Climate Action (ECA) Commission to future-proof the living landscape against the impacts of rapid environmental change. It concludes with a call for more real-time information on the needs and demands of different user groups to overcome barriers, and also for specific improvements in user service networks.

\section{Conventional Urban Design Practice}

Since the launch of the ecosystem services assessment framework in 2005 (see Millennium Ecosystem Assessment, 2005), advances have been made in the development of ecosystem services cascade models (Hubacek \& Kronenberg, 2013; Luederitz et al., 2015), but progress in accounting of services for urban green spaces lags behind studies on other ecosystems, particularly when it comes to promoting ecosystem function, structure, and network patterns (Haase et al., 2014). In part, this can be attributed to a lack of understanding within planning departments of the relationship between key ecological attributes (KEA), ecosystem function, and the cultural values attributed to urban green infrastructure (Artmann et al., 2017; Luederitz et al., 2015). Consequently, few green infrastructure plans demonstrate an ecosystem-based approach with clear links between ecological and social benefits (Daniel et al., 2012; Haase et al., 2014; Kremer et al., 2016). For many urban planners, the multiple use of urban spaces and the diversity of cultural services make it difficult to apply ecosystem-based models such as the Common International Classification of Ecosystem Services (Costanza et al., 2014; Haines-Young \& Potschin, 2017; Kumar et al., 2014), and to deliver payment for ecosystem services (Reed et al., 2017; The Economics of Ecosystems and Biodiversity, 2010, 2011; URS, 2013).

The Economics of Ecosystems and Biodiversity, the European Environmental Bureau, and the Common International Classification of Ecosystem Services (Maes et al., 2014, 2016) are designed to assess natural capital and the preservation of ecological assets as well as safeguard ecosystem services at both regional and national scales. A similar certification scheme, the Sustainable Sites Initiative (SITES) makes explicit the importance of adhering to performance-based guidelines and tasks designers with setting specific goals for the conservation of services (Calkins, 2012; SITES, 2015). The practical guidelines presented in SITES consist mainly of quantitative measures of performance (Windhager et al., 2010) and focus on sustainable land design, but are not specifically intended to assess whole ecosystem function and services networks.

Many green planning models launched in recent years under the banner of "eco-urbanism" apply novel technical solutions to remedy environmental problems (Lennon et al., 2017). Examples include large scale river restoration programmes, sustainable urban drainage schemes (SUDS), and engineering projects such as green and blue space adaptation for urban areas and eco towns (Town and Country Planning Association London, 2015). However, many of these initiatives have yet to be developed into a fully integrated plan for eco-social infrastructure. More recently, the Directorate-General for Research and Innovation (2015) has adopted the concept of nature-based solutions to restore degraded ecosystems and promote improved derived services as well as making them adaptive to climate change (Cohen-Schacham et al., 2016; Nesshöver et al., 2017). The potential for nature-based solutions to increase urban resilience and improve social wellbeing is affirmed in the Commission's strategy for green infrastructure but is not complemented by appropriate theory-to-practice models and toolkits necessary for effective implementation (Bush \& Doyon, 2019).

Published in 2014, the European Commission strategy for green spaces titled Green InfrastructureEnhancing Europe's Natural Capital was launched with the objective of delivering a wide range of ecosystem services as part of spatial planning and urban development (European Commission, 2014). The strategy also aims to assess understanding and guidance for decision-makers and civil society on the principles and application of ecosystem-based approaches. The potential for integrating ecosystem-based approaches into urban planning is 
clear but is yet to be fully developed in both research and practice. Gaps remain in both understanding and experience in implementing urban planning processes that deliver wide-ranging ecological benefits as well as social value (Bush \& Doyon, 2019).

\section{Developing Conceptual Models for Sustainable Urban Green Infrastructure}

Hierarchical network models are used extensively in business studies and ecosystem theory (see Jørgensen et al., 2015), but have yet to make headway in the world of design and planning. Part of the problem is the difficulties perceived by practitioners in translating an essentially scientific concept into a very technical design format (Luederitz et al., 2015). Conventional approaches used in the design of urban space are spatially represented in two-dimension cartographic form with the emphasis on location; relationship to other spaces and structures; and use of open space by the community for recreation. Until now, there has been little occasion for thinking more holistically about the functional role of urban green infrastructure and how this might influence location, juxtaposition with other features, scale, and connectivity across the urban landscape and beyond into the rural domain. Hierarchical and deeply interconnected representations of urban green infrastructure encourage practitioners to consider the use and design of space in three dimensions. For example, the fundamental geophysical elements of a landscape are linked to derived cultural values through a network of forms contributing to complex processes that make up the function of the ecosystem and provide the necessary services.

We propose two interrelated conceptual models as part of the ecosystem-based approach to urban design and planning, which are urban green space framework (UGSF) and sustainable urban community network (SUCN).

The UGSF model describes and characterises the physical nature and attributes of urban space using ecosystem theory and principles of complex systems. It adopts a meta-systemic approach using KEA (see Schick et al., 2019) as proxy indicators for ecosystem function. Six KEA of relevance to green infrastructure planning are presented below:

- Scale: The minimum dynamic area required for partial or all basic ecosystem functions and processes. It is determined by the ecological envelope of the (semi-)natural system;

- Hierarchy: It recognises that nature is assembled hierarchically. Permeations between scale breaks ensures flow of material and energy;

- Networks: Components of the ecosystem are interlinked. Change in status of a component will affect the whole system;

- Information: The capacity for an ecosystem to selforder and maintain function over time is contin- gent on the structural, genetic, and behavioural diversity within;

- Biomass: Productivity, longevity, adaptability, resilience, and resistance to change is dependent on "exergy" - useful material and energy stored in a system;

- Dynamics: Vital processes driving growth and function of an ecosystem are dominated by non-linear, feedback dynamics.

Holling (1998, p. 4) maintains that systems are moving targets, suggesting they are complex and dynamic. The function of ecosystems is dependent on profound connectivity between all its contingent components and is governed by non-linear processes (Holling, 2000). In an urban context, biomass is represented by the total accumulation of biological organic matter residing in all forms of green infrastructure, while networks and information describe form and function of biodiversity: the species, interactions between them, and the processes governing material flows and cycles. Growth towards greater complexity provides a system with resilience, and, in nature, increases the potential services drawn down by society. More recently, scientists have used concepts of ecosystem thermodynamics and complex systems theory to explain natural systems dynamics (see Demirel, 2014; Kleidon \& Lorenz, 2005; Lebon et al., 2008). In accordance with these theories, natural ecosystems are open, allowing for energy and material to flow freely between them, and, under healthy conditions, each ecosystem can self-order through feedback processes enabling them to conserve energy and prevent dramatic regime shifts or even collapse-entropy (Kay et al., 2001; Norris et al., 2011).

All six ecological attributes relate systemically to generate the structure, growth, function, and ultimately resilience of ecosystems. The capacity for ecosystem evolution and adaptation is contingent on scale and the efficiency of components and networks in capturing, dissipating, storing, and using energy. The UGSF helps to structure, translate, and integrate theories of thermodynamics and complex systems into urban green space planning and assessment, and also provides a baseline for generating nature-based solutions for deep rooted design problems manifest in compact cities.

The SUCN model applies a community- and stakeholder-based approach to design and planning of urban green infrastructure. The growing popularity of civic stewardship enables communities to act as managers of urban open spaces and encourages the local community to value these areas for the service(s) they provide (Connolly et al., 2014). Incorporating fundamental aspects of UGSF into a planning strategy designed to identify relevant service algorithms for different societal goals may deliver a more effective means of facilitating networked governance processes, and building collaboration between public sector, private enterprises, and civic stewardship groups. The SUCN model is an 
ecosystem-based but urban-driven open framework specially designed for co-working on different elements of system growth towards the formulation of environmental sustainability and human wellbeing. Ecosystem services hierarchy model emphasizes the dependency of cultural services on regulating and provisioning services (Figure 1). At the top of a "services hierarchy" are the cultural services, and these are contingent on the effective functioning of the ecosystem, which, in turn, is dependent on the status of ecological attributes. Increasing rates of environmental change coupled with growing pressures from rapidly shifting socioeconomic and political baselines require planning solutions that are both integrated and systemic across all levels of the cultural landscape (Schick et al., 2017). The SUCN framework is based on a systemic analysis technique called MARISCO (see Ibisch \& Hobson, 2014) and harnesses the participatory efforts of the target community to implement contextualized actions that promote adaptive management planning across human-ecosystem interfaces. Participatory modelling methods can support systems thinking in practice by facilitating shared understanding and knowledge of the structure and dynamics inherent in complex socio-ecological landscapes (Duboz et al., 2018). Implementing SUCN is a collective endeavour. In the last two decades, community-based action has played a fundamental part in the development of strategies for sustainable land use and building effective coalition within communities requires large scale participatory strategies that favour a non-dominant culture (Hubacek \& Mauerhofer, 2008). The role of town and city municipalities in forging the establishment of "land trusts" - private-public property regimes or partnerships that permit greater shared control over use of urban green space-is essential to the process.

Both models, UGSF and SUCN, represent the natural and cultural components of a deeply interconnected complex ecosystem. The status and condition of the KEA determines the functional effectiveness of the ecosystem which in turn regulates the services derived by the local community. Human intervention or impact at any level or point in the ecosystem will result in both linear and non-linear meta-systemic feedback dynamics. An example of the cascade effect between natural and human attributes in cultural ecosystems is evident in many historical European cities that are characterised by well-established public gardens and parks with water bodies and avenues of mature shrubs and trees.

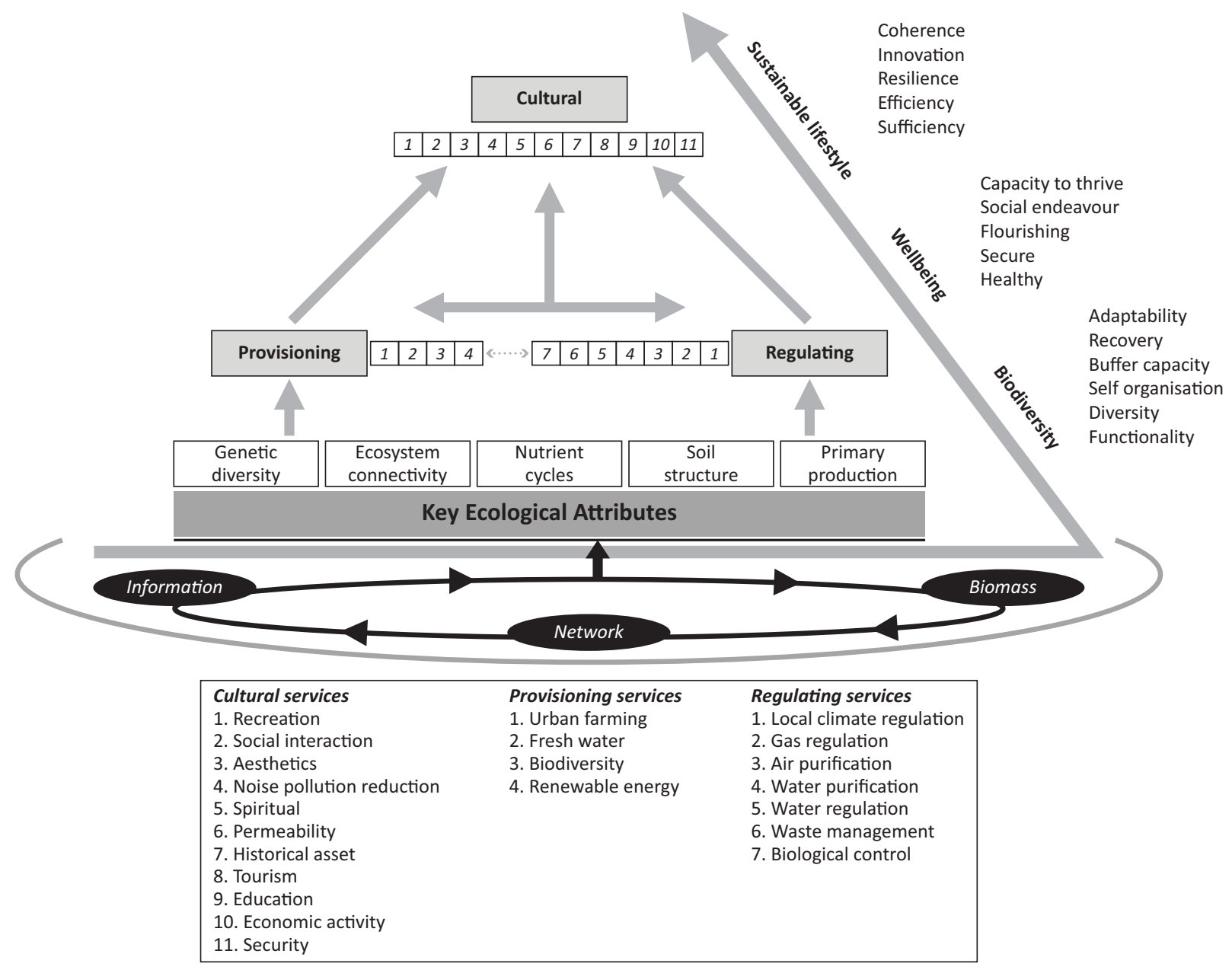

Figure 1. Ecosystem services hierarchy model emphasises the dependency of cultural services on regulating and provisioning services. A sustainable lifestyle is contingent on maintaining effective ecological structure and function. 
A number of native wildlife species have adapted to urban conditions and contributed towards improving the function of ecosystems, enabling them to degrade (capture and use of energy) incoming solar radiation more effectively, thus improving thermal comfort, air quality, urban drainage, and human wellbeing (Tratalos et al., 2007). Recent research suggests that people who move to greener urban areas are associated with significant sustained improvement in health (Alcock et al., 2014).

The two-model approach to ecosystem-based design and planning embraces concepts of spatial and functional complementarity that require a set of heuristic design principles to help transition theory into practice. We propose six design principles for ecosystembased design and planning for urban green infrastructure, which are the following:

1. Recognise and work within the natural spatial and temporal scales of the ecosystem, and take account of ecological dynamics that produce varying temporal scales and lag-effects (includes natural succession, ecosystem and species lifecycles, plant, and animal species-area relationships);

2. Ensure the conservation of ecosystem structure and function across natural space-time scales with particular attention to biomass, natural networks and connectivity, and the diversity of natural forms (includes diversity of native species and functional groups, natural patch diversity and heterogeneity, natural biomass production and storage above and below ground, hydrological regime, and hydro-geomorphological dynamics);

3. Take account of both short and long-term ecosystem changes that may affect function-area dynamics, species-area relationships, flow of energy and materials through an ecosystem, species persistence, and ecosystem resilience;

4. Consider ecological integrity of the target site by adopting a meta-systemic perspective that takes account of the relationships with adjacent sites and ecosystems in the neighbourhood and wider landscape;

5. Involve all relevant members of society and academia in a community-based participatory approach and consider all forms of pertinent knowledge and information;

6. Play an integral part of larger structure plans with a clear understanding of the contribution made to wider landscape ecosystem function by developing site-specific sustainable ecosystem-based planning.

\section{A Case Study: Essex Climate Action Recommendations for Green Infrastructure}

In 2020, the Essex County Council, located in the east of England, established a climate action commission to help develop an ambitious strategy to combat the problems of climate change. The Commission consists of a multi- stakeholder group of experts from a wide range of disciplines, including scientists and practicing professionals in agriculture, urban development, and water resource management (ECA Commission, 2021). A priority field for the Commission is to develop recommendations for green infrastructure with the aim of achieving, by 2030 and 2050, a transformation in the way land is managed in order to deliver the target for net zero carbon as quickly as possible (ECA Commission, 2021). In their example, the Essex County Council adopts a broad description for green infrastructure that includes natural and rural land cover types. The recommendations propose an integrated ecosystem-based approach with the purpose of delivering multiple benefits to local communities including nature recovery, improved soil health, improved air and water quality, reduction in flooding and urban heat island effects, and gains in human wellbeing by increasing amenity opportunities. One of the key recommendations is to manage $30 \%$ of all land in Essex as a natural green infrastructure to promote the enhancement of biodiversity and the natural environment: $25 \%$ by 2030 and $30 \%$ by 2040 . Another recommendation is to create $30 \%$ greening of our town, villages, and new developments by: increased greenspace creation, naturalising existing green space, greening the public realm, and developing SUDS (ECA Commission, 2021).

A key recommendation for climate action is the establishment of a climate focus area (CFA), representing $30 \%$ of landcover for Essex, and taking in the catchments of the Blackwater and Colne rivers (Figures 2 and 3). The total population within both catchment areas is approximately 901,700 , with 307,600 people located in the main cities and towns, including Colchester. The remainder are scattered across villages, hamlets, and isolated farm settlements. River catchments are large scale features dominated by the ongoing dynamics of rivers and wetlands. Many continue to support rich environmental legacies and provide essential connectivity in modified landscapes. The projection for the greater Essex population increase is over $18 \%$ to approximately 2.1 million by 2040 which will put greater pressure on the existing landscape resources. Across Europe, almost all catchments have been altered by land use change but continue to provide important ecosystem services to settlements. The CFA represents a hierarchically organised and interconnected ecosystem and a model for landscape scale design and planning for green infrastructure. The thinking behind the selection of a defined area of operation is pivoted on the biosphere reserve concept of developing sustainable solutions for the multiple use of natural resources where conflicts of interest frequently impact on both environmental conditions and social wellbeing. Targeting a designated area encourages investment in more intensive and focused action but also opens opportunities to develop and implement integrative strategic planning. In the case of the Essex CFA, recommendations for accelerating sustainable farming methods and transitioning local food systems, and for 


\section{COGITATIO}

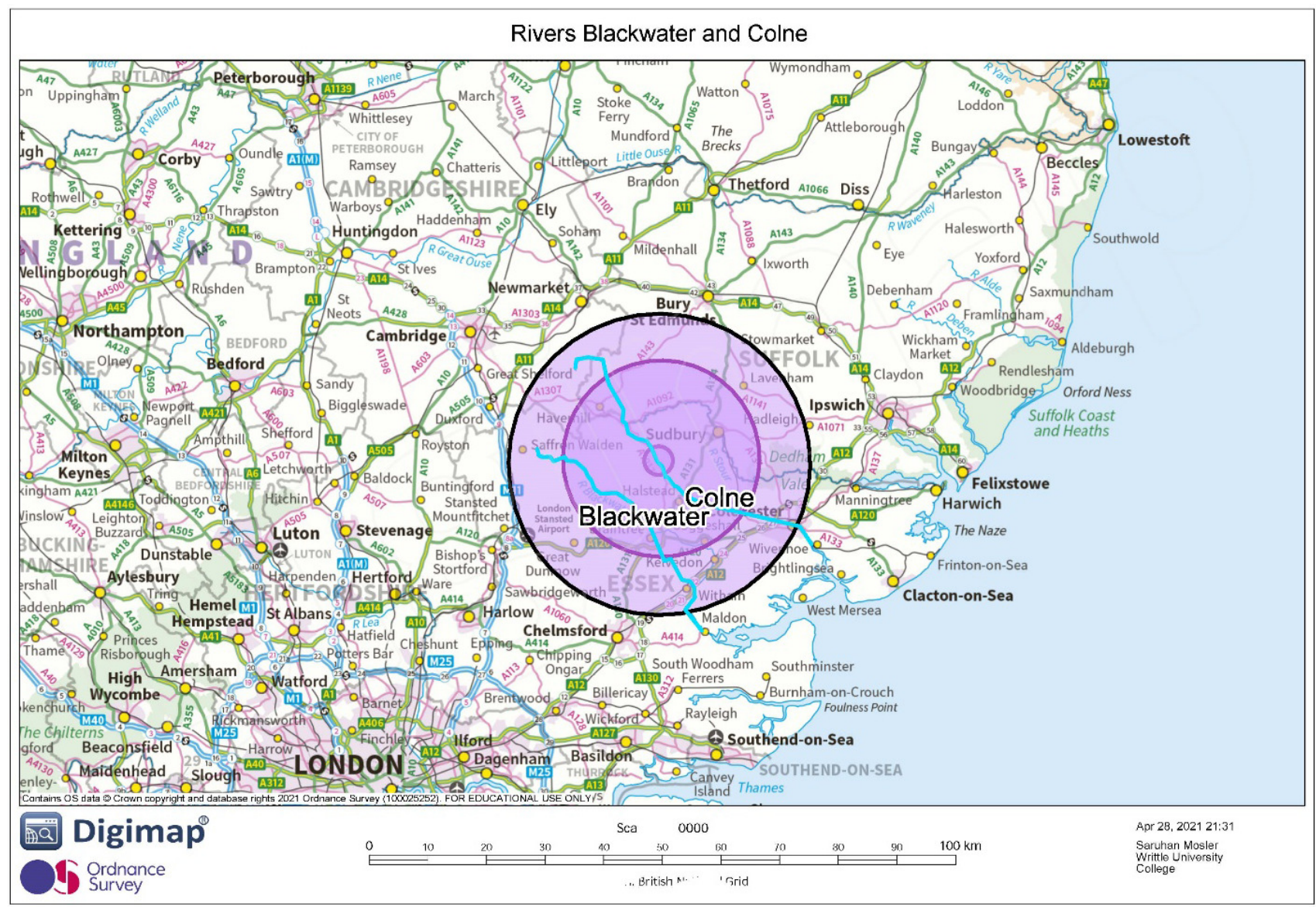

Figure 2. Rivers Blackwater and Colne in Essex. Source: Authors' work, modified after Digimap (https://digimap.edina.ac.uk).

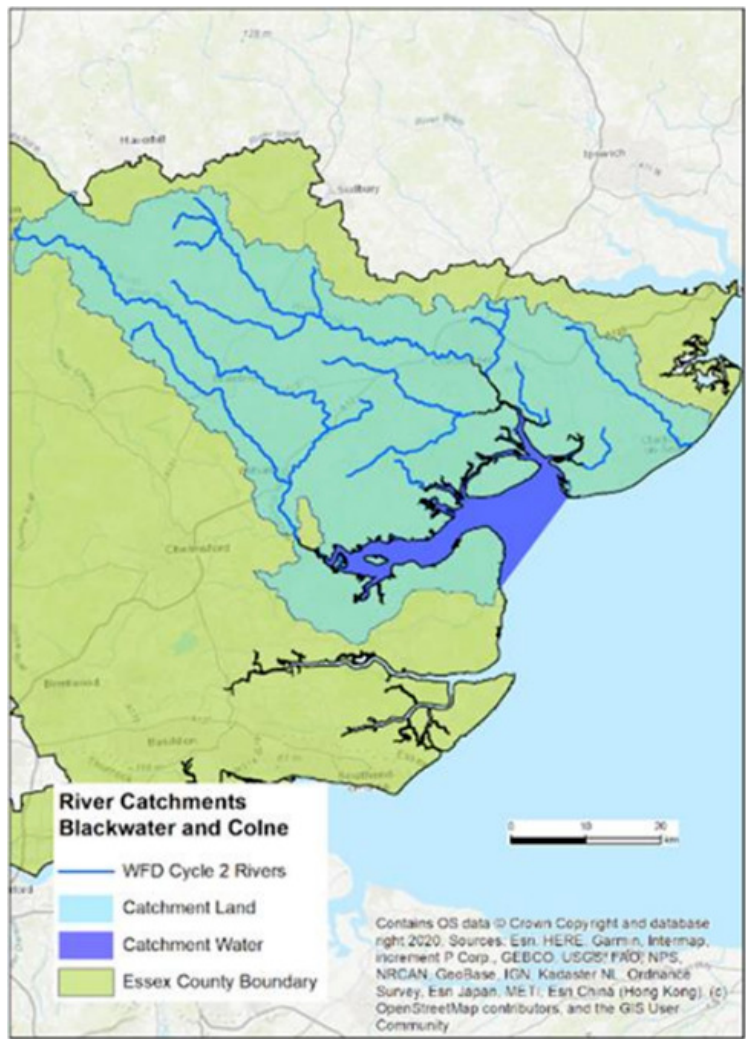

Figure 3. The proposed CFA for Essex. The chosen areas comprise the Colne and Blackwater catchments and together make up $30 \%$ of the county (ECA Commission, 2021). Source: Spains Hall Estate (n.d.). 
developing nature-based solutions to mitigate flood risks and rolling out far-reaching nature recovery strategies are integrated with strategies for generating innovative green business and for transforming transport, the built environment, and energy and waste sectors towards circular, zero carbon systems. Recommendations for the CFA are set out as 2030 targets and include every parish to have biodiversity and climate emergency action plans, $30 \%$ of urban areas to be under natural green infrastructure, a doubling of native tree cover, and $30 \%$ of land cover to be managed as a natural green infrastructure (ECA Commission, 2021).

The success of ECA with all the inherent complexities of operating in a multipurpose landscape is contingent on public engagement across all levels of society. Community participatory planning is designed to enable and support community groups, schools, individuals, and businesses to innovate and implement climate actions they identify for themselves; to harness local knowledge and build local support to achieve sustainable land stewardship and natural green infrastructure recommendations; and to develop a strategy for working within communities from the start to ensure local inclusion and accountability. It is being used across Essex to facilitate the launch of a co-creative steering group of local community stakeholders, local government networks, specialists, and others to map further participation and inclusion within the county and to establish terms of reference. It is also being deployed to map and record existing activities of various sections of society (e.g., NGOs, schools, and parish councils), to establish a campaign strategy to support individual, business and community action with short term identified goals leading to longer term goals by 2050 , and to create a framework for local groups to become independent in developing activities, communications, feedback, and future planning across the county (ECA Commission, 2021). Participatory planning that involves stakeholder workshops and community action groups is a systematic approach that draws together a spatial assessment of specified land cover typologies, and detailed situation analysis of the ecosystem services and benefits derived from natural attributes together with an evaluation of the vulnerabilities manifest in human use and influences (see Ibisch \& Hobson, 2014). Through a process of situation analysis participants are better able to understand the deeply integrated nature of landscapes: the dependency of human wellbeing on natural ecosystem function, and the vulnerability of interdependent systems to human-induced disturbance.

The ECA recognizes multifunctionality of green infrastructure including climate, biodiversity, health and wellbeing of citizens, and flood mitigation in the sustainable future planning and design of urban landscapes. Therefore, designed landscapes are an integral part of the green network and through careful design and planning can contribute to defragmentation and landscape restoration. The benefits derived from a fully integrated and networked green infrastructure will be wide-ranging environmental and cultural services. Table 1 presents the key summary of the evaluation of ECA vision set through our proposed heuristic design principles to help transition theory into practice. Key summary presents aspects that ECA can achieve, recognize, and develop further for the ecosystem-led planning and design for the county of Essex.

Table 1. ECA and heuristic design principle evaluation chart. This table shows the evaluation of ECA recommendations through theoretical application of proposed heuristic design principles to the ECA recommendations. The key summary demonstrates proposed action points for the ECA recommendations with an enhanced approach to ecosystem-led planning and design.

ECA for Green
Infrastructure (ECA

Commission, 2021)

Land use: Farmland in

Essex to adopt

sustainable land stewardship practices, $50 \%$ by $2030,75 \%$ by 2040 , and $100 \%$ by 2050 .
Proposed Heuristic Design Principles

(1) Recognise and work within the natural spatial and temporal scales of the ecosystem and take account of ecological dynamics that produce varying temporal scales and lag-effects (includes natural succession, ecosystem, and species lifecycles);

(2) Ensure the conservation of ecosystem structure and function across natural space-time scales with particular attention to biomass, natural networks and connectivity, and the diversity of natural forms (includes diversity of native species and functional groups, natural patch diversity and heterogeneity, natural biomass production and storage above and below ground, hydrological regime, and hydro-geomorphological dynamics).
Key Summary

- Avoid the unnecessary use of external inputs;

- Harness agroecological processes such as nutrient cycling, biological nitrogen fixation, allelopathy, predation, and parasitism;

- Minimise use of technologies or practices that have adverse impacts on the environment and human health;

- Utilise crop varieties and livestock breeds with a high ratio of productivity to use of externally and internally derived inputs. 
Table 1. (Cont.) ECA and heuristic design principle evaluation chart. This table shows the evaluation of ECA recommendations through theoretical application of proposed heuristic design principles to the ECA recommendations. The key summary demonstrates proposed action points for the ECA recommendations with an enhanced approach to ecosystem-led planning and design.

ECA for Green

Infrastructure (ECA

Commission, 2021)

Biodiversity: $30 \%$ of all land in Essex will enhance biodiversity and the natural environment by creating natural green infrastructure, $25 \%$ by 2030 and $30 \%$ by 2040 .

$$
\text { Proposed Heuristic Design Principles }
$$

Key Summary

(2) Ensure the conservation of ecosystem structure and function across natural space-time scales with particular attention to biomass, natural networks and connectivity, and the diversity of natural forms (includes diversity of native species and functional groups, natural patch diversity and heterogeneity, natural biomass production and storage above and below ground, hydrological regime, and hydro-geomorphological dynamics).
- Create a nature recovery network, using natural river corridors, the coast, other green linear features, and new green infrastructure to establish effective interlinked wildlife corridors across the county;

- Integrate nature gain strategies into planning and management of all working and cultural landscapes;

- Each parish to produce a complementary and integrated biodiversity action plan.
Flooding: For those properties still at risk of flooding, $75 \%$ of integrated water management and natural flood management will be developed to increase resilience by 2050

(1) Recognise and work within the natural spatial and temporal scales of the ecosystem and take account of ecological dynamics that produce varying temporal scales and lag-effects (includes natural succession, ecosystem, and species lifecycles);

(3) Take account of both short- and long-term ecosystem changes that would affect function-area dynamics, species-area relationships, flow of energy and materials through an ecosystem, species persistence, and ecosystem resilience.

\section{(2) Ensure the conservation of ecosystem} structure and function across natural space-time scales with particular attention to biomass, natural networks and connectivity, and the diversity of natural forms (includes diversity of native species and functional groups, natural patch diversity and heterogeneity, natural biomass production and storage above and below ground, hydrological regime, and hydro-geomorphological dynamics). realm, and developing SUDS.

CFA: Create a CFA to accelerate action and provide exemplars, adopting sustainable land stewardship practices $(100 \%$ by 2030) and natural green infrastructures (30\% by 2030 ).
(4) Consider ecological integrity of the target site by adopting a meta-systemic perspective that takes account of the relationships with adjacent sites and ecosystems in the neighbourhood and wider landscape.
- Nature based flood solutions create large areas of natural green infrastructure;

- Natural green infrastructure allows water to percolate into groundwater improving water quality and reserves;

- Natural green infrastructure acts as a huge sponge for water: growing plants, sucking up water and organic soils, and absorbing water;

- Linear river and coastal nature-based flood schemes create wildlife corridors which enhance biodiversity and contribute to nature recovery networks.

- Increases biodiversity and creates wildlife corridors ("green veins" and

"greening-the-grey");

- Lowers the "heat Island effect" in built up areas;

- Provides "green-exercise" benefits to mental health;

- Reduces pollution;

- SUDS reduces urban flooding.

- To serve as a pathfinder and pilot area, accelerating best practice in sustainable land management;

- To act as an investment "attractor" for innovative green business and for pioneering new sustainable farming methods;

- A focus area for transitioning local food systems and cultural eating habits;

- To demonstrate ambitious and sustained nature recovery strategies;

- A multi-sectoral project site for integrating and intensifying action following recommendations from the special interest groups (transport-built environment, energy and waste, and community). 
Table 1. (Cont.) ECA and heuristic design principle evaluation chart. This table shows the evaluation of ECA recommendations through theoretical application of proposed heuristic design principles to the ECA recommendations. The key summary demonstrates proposed action points for the ECA recommendations with an enhanced approach to ecosystem-led planning and design.

ECA for Green

Infrastructure (ECA

Commission, 2021)

Engagement: Ensure

collaboration and

engagement by

carrying out a

participatory

community process,

catalysing communities,

farmers, landowners,

and individuals, and

encouraging personal

and community action

in the CFA and the

whole of Essex.

Knowledge and

Decision Support:

Developing effective

monitoring and

evaluation, an

integrated

sustainability appraisal

framework, an Essex

climate observatory,

and a knowledge and

decision support

framework.

Proposed Heuristic Design Principles

Key Summary

(5) Should involve all relevant members of society and academia in a community-based participatory approach and consider all forms of pertinent knowledge and information.
- Enable and support community groups, schools, individuals and businesses to innovate and implement climate actions they identify for themselves;

- Harness local knowledge and build local support to achieve sustainable land stewardship and natural green infrastructure recommendations;

- Develop a strategy working within communities from the start to ensure local inclusion and accountability.

(5) Should involve all relevant members of
society and academia in a community-based
participatory approach and consider all forms
of pertinent knowledge and information.

(5) Should involve all relevant members of society and academia in a community-based of pertinent knowledge and information.
- Develop a monitoring and evaluation
programme within an Essex climate
observatory and involve citizens and
researchers in data gathering activities
across the CFA;
- Develop an integrated sustainability
appraisal framework to support the
Climate Action Programme in Essex,
the CFA, and stakeholders needs;
- Collate and curate relevant data within an
Essex knowledge platform and decision
support framework;
- Establish a baseline audit for the CFA.

\section{Conclusions}

To help mitigate the problems of urban growth and densification, urban planners and designers have recently been using a range of models for urban green infrastructure to provide sustainable, resilient, and healthy urban environments. Notwithstanding, the need remains to strengthen the framework for design and planning by structuring it around ecosystem-based approaches. An ecosystem approach to planning is predicated on the physical and biological structures and processes that determine the function of ecosystems and ultimately support human wellbeing; however, there are few examples of urban green infrastructure design that demonstrate the complex interrelationship between ecological function and social wellbeing. In part, this may be attributed to the lack of heuristic design principles for urban green infrastructure that draw on an understanding of the relationship between specific ecological and social concepts. Ecology already has a wide application in landscape architecture and planning with a strong focus on species persistence and movement, patch dynamics, connectivity, and disturbance patterns. Less attention is given to ecosystem growth, function, and dynamics, or to ecosystem thermodynamics, and for obvious reasons. The mathematical and empirical nature of ecosystem theory is complicated enough for scientists without attempting to translate into language and practical models for landscape architects and planners. Nevertheless, a more comprehensive understanding among landscape architects and planners of ecosystem science is necessary if resilient and sustainable conditions are to be provided for urban communities, and if current policies and directives for safeguarding the environment and mitigating problems of climate change are to be met.

The purpose of heuristic principles is to help translate theory into models of practice but, even then, it is often necessary to justify and explain the origins and content of principles. The two models offered in our article, UGSF and SUCN, provide appropriate criteria and framing for the heuristic principles. Both models represent the two main domains of living landscapes: the natural and cultural environments, and are mutually complementary by virtue of the interconnectedness and systemic nature 
of ecosystems and communities. For instance, the process of conducting community participation encourages knowledge sharing and learning between all members of society, from scientists to managers and policy makers. Information is collectively assessed systemically before it is evaluated through consensus and finally translated into agreed plans and strategies. Community participatory planning is carried out in the context of the environmental setting - the physical character of the landscape. In other words, the KEA are evaluated within a broad understanding of nature-based values people attach to green infrastructure. The ECA recommendations represent the role of ecosystem-led planning approach at all scales and levels, including smaller scale interventions to larger rural planning approach, to create a robust green infrastructure system across the county. The vision and targets for green infrastructure set out by ECA Commission reflect clearly three principles of an ecosystem-based approach: First, by adopting a landscape approach to planning, the patterns and processes lending structure and driving change are better understood; second, by working with the grain of nature, outcomes are more likely to be sustainable and resilient; and third, to achieve a coherent and fully integrative strategy, a bottom-up, full participatory approach is a prerequisite. Finally, an ecosystem approach also facilitates learning within the community. It encourages knowledge sharing, continual evaluation, and adaptation, essential attributes for operating in situations that are rapidly changing.

The relationship between humans and the environment has increased levels of complexity and vulnerability in natural ecosystems to the extent of precipitating rapid climate change and plummeting decline in biodiversity (Intergovernmental Panel on Climate Change, 2019; Schick et al., 2017). Until recently, socio-environmental problems were analysed and addressed using linear, cause-effect principles, and took little account of the deeply interconnected nature and non-linear character of ecosystems. Recent changes in the way science analyses complex systems have opened up opportunities to develop holistic models for land use design, planning, and management. Innovative design and new methods of practice will have to demonstrate flexibility, adaptability, and systemic function if we are to future-proof our living landscapes.

\section{Conflict of Interests}

The authors declare no conflict of interests.

\section{References}

Alcock, I., White, M. P., Wheeler, B. W., Fleming, L. E., \& Depledge, M. H. (2014). Longitudinal effects on mental health of moving to greener and less green urban areas. Environmental Science \& Technology, 48(2), 1247-1255. https://doi.org/10.1021/es403688w
Artmann, M., Bastian, O., \& Grunewald, K. (2017). Using the concepts of green infrastructure and ecosystem services to specify Leitbilder for compact and green cities-The example of the landscape plan of Dresden (Germany). Sustainability, 9(2), Article 198. https://doi.org/10.3390/su9020198

Bertram, C., \& Rehdanz, K. (2015). The role of urban green space for human well-being. Ecological Economics, 120, 139-152.

Bush, J., \& Doyon, A. (2019). Building urban resilience with nature-based solutions: How can urban planning contribute? Cities, 95, Article 102483. https:// doi.org/10.1016/j.cities.2019.102483

Calkins, M. (2012). The sustainable sites handbook. Wiley.

Cohen-Schacham, E., Walters, G., Janzen, C., \& Maginnis, S. (Eds.). (2016). Nature-based solutions to address global societal challenges. International Union for Conservation of Nature.

Connolly, J. J. T., Svendsen, E. S., Fisher, D. R., \& Campbell, L. K. (2014). Networked governance and the management of ecosystem services: The case of urban environmental stewardship in New York City. Ecosystem Services, 10, 187-194.

Costanza, R., de Groot, R., Sutton, P., van der Ploeg, S., Anderson, S. J., Kubiszewski, I., Farber, S., \& Turner, R. K. (2014). Changes in the global value of ecosystem services. Global Environmental Change, 26, 152-158. https://doi.org/10.1016/j.gloenvcha.2014.04.002

Daniel, T. C., Muhar, A., Arnberger, A., Aznar, O., Boyd, J. W., Chan, K. M. A., Costanza, R., Elmqvist, T., Flint, C. G., Gobster, P. H., Gret-Regamey, A., Lave, R., Muhar, S., Penker, M., Ribe, R. G., Schauppenlehner, T., Sikor, T., Soloviy, I., Spierenburg, M., \& Taczanowska, K. (2012). Contributions of cultural services to the ecosystem services agenda. Proceedings of the National Academy of Sciences, 109(23), 8812-8819. https://doi.org/10.1073/pnas. 1114773109

Dasgupta, P. (2021). The economics of biodiversity: The Dasgupta review-Abridged version. HM Treasury.

Demirel, Y. (2014). Nonequilibrium thermodynamics. Transport and rate processes in physical, chemical and biological systems. Elsevier.

Department of Economic and Social Affairs. (2018). The world's cities in 2018-Data booklet (ST/ESA/SER.A/417). United Nations. https://www. un.org/en/events/citiesday/assets/pdf/the_worlds_ cities_in_2018_data_booklet.pdf

Directorate-General for Research and Innovation. (2015). Towards an EU research and innovation policy agenda for nature-based solutions \& re-naturing cities: Final report of the horizon 2020 expert group on "nature-based solutions and re-naturing cities." European Commission.

Duboz, R., Echaubard, P., Promburom, P., Kilvington, M., Ross, H., Allen, W., Ward, J., Deffuant, G., de GarineWichatitsky, M., \& Binot, A. (2018). Systems think- 
ing in practice: Participatory modeling as a foundation for integrated approaches to health. Frontiers in Veterinary Science, 5, Article 303. https://doi.org/ 10.3389/fvets.2018.00303

Essex Climate Action Commission. (2021). Essex Climate Action Commission: Land use \& green infrastructure. Technical annex. Essex County Council. https:// assets.ctfassets.net/knkzaf64jx5x/3dW3CnB3EpMAg TXeqXGTuh/b76471e8b4b49ac2488ca7e67832df81/ Climate-Action-Annex-Land-Use-and-GreenInfrastructure.pdf

European Commission. (2014). Communication from the commission to the European Parliament, the Council, the European Economic and Social Committee and the Committee of the Regions: Green infrastructure (GI)-Enhancing Europe's natural capital (COM/2013/0249). https://eur-lex.europa.eu/legalcontent/EN/TXT/?uri=CELEX:52013DC0249

Grahn, P., \& Stigsdotter, U. A. (2003). Landscape planning and stress. Urban Forestry and Urban Greening, 2(1), 1-18.

Haase, D., Larondelle, N., Andersson, E., Artmann, M., Borgström, S., Breuste, J., Gomez-Baggethun, E., Gren, Å., Hamstead, Z., Hansen, R., Kabisch, N., Kremer, P., Langemeyer, J., Rall, E. L., McPhearson, T., Pauleit, S., Qureshi, S., Schwarz, N., Voigt, A., \& Wurster, D. (2014). A quantitative review of urban ecosystem service assessments: Concepts, models, and implementation. AMBIO, 43(4), 413-433. https://doi.org/10.1007/s13280-014-0504-0

Haines-Young, R., \& Potschin, M. (2017). Common international classification of ecosystem services (CICES) V5.1. Guidance on the application of the revised structure. Fabis Consulting Ltd.

Holling, C. S. (1998). Two cultures of ecology. Conservation Ecology, 2(2), Article 4.

Holling, C. S. (2000). Theories for sustainable futures. Conservation Ecology, 4(2).

Hubacek, K., \& Kronenberg, J. (2013). Synthesizing different perspectives on the value of urban ecosystem services. Landscape and Urban Planning, 109, 1-6.

Hubacek, K., \& Mauerhofer, V. (2008). Future generations: Economic, legal and institutional aspects. Futures, 40(5), 413-423.

Ibisch, P. L., \& Hobson, P. R. (Eds.). (2014). MARISCO. Adaptive MAnagement of vulnerability and RISk at COnservation sites. A guidebook for risk-robust, adaptive and ecosystem-based conservation of biodiversity. Centre for Econics and Ecosystem Management.

Intergovernmental Panel on Climate Change. (2019). 2019. https://www.ipcc.ch/2019

Jørgensen, S. E., Nielsen, S. N., \& Fath, B. D. (2015). Recent progress in systems ecology. Ecological Modelling, 319, 112-118.

Kabisch, N., Frantzeskaki, N., Pauleit, S., Naumann, S., Davis, M., Artmann, M., Haase, D., Knapp, S., Korn, H., Stadler, J., Zaunberger, K., \& Bonn, A. (2016). Naturebased solutions to climate change mitigation and adaptation in urban areas: Perspectives on indicators, knowledge gaps, barriers, and opportunities for action. Ecology and Society, 21(2), Article 39. https:// doi.org/10.5751/es-08373-210239

Kasanko, M., Barredo, J. I., Lavalle, C., McCormick, N., Demicheli, L., Sagris, V., \& Brezger, A. (2006). Are European cities becoming dispersed? A comparative analysis of 15 European urban areas. Landscape and Urban Planning, 77, 111-130.

Kay, J. J., Allen, T., Fraser, R., Luvall, J. C., \& Ulanowicz, R. E. (2001). Can we use energy-based indicators to characterize and measure the status of ecosystems, human, disturbed and natural? In S. Ulgiati, M. T. Brown, M. Giampietro, R. A. Herendeen, \& K. Mayumi (Eds.), Advances in energy studies: Exploring supplies, constraints and strategies (pp. 121-133). SGEditoriali.

Kleidon, A., \& Lorenz, R. D. (Eds.). (2005). Nonequilibrium thermodynamics and the production of entropy. Springer.

Koomen, E., \& Diogo, V. (2015). Assessing potential future urban heat island patterns following climate scenarios, socio-economic developments and spatial planning strategies. Mitigation and Adaptation Strategies for Global Change, 22(2), 287-306. https://doi.org/10.1007/s11027-015-9646-z

Kremer, P., Hamstead, Z., Haase, D., McPhearson, T., Frantzeskaki, N., Andersson, E., Kabisch, N., Larondelle, N., Rall, E. L., Voigt, A., Baró, F., Bertram, C., Gómez-Baggethun, E., Hansen, R., Kaczorowska, A., Kain, J.-H., Kronenberg, J., Langemeyer, J., Pauleit, S., \& Rehdanz, K. (2016). Key insights for the future of urban ecosystem services research. Ecology and Society, 21(2), Article 29. https://doi.org/10.5751/ es-08445-210229

Kumar, P., Kumar, M., \& Garrett, L. (2014). Behavioural foundation of response policies for ecosystem management: What can we learn from payments for ecosystem services (PES). Ecosystem Services, 10, 128-136.

Lebon, G., Jou, D., \& Casas-Vázquez, J. (2008). Understanding non-equilibrium thermodynamics: Foundations, applications, frontiers. Springer.

Lennon, M., Douglas, O., \& Scott, M. (2017). Urban green space for health and well-being: Developing an "affordances" framework for planning and design. Journal of Urban Design, 22(6), 778-795. https://doi. org/10.1080/13574809.2017.1336058

Luederitz, C., Brink, E., Gralla, F., Hermelingmeier, V., Meyer, M., Niven, L., \& Von Wehrden, H. (2015). A review of urban ecosystem services: Six key challenges for future research. Ecosystem Services, 14, 98-112.

Maes, J., Liquete, C., Teller, A., Erhard, M., Paracchini, M. L., Barredo, J., \& Lavalle, C. (2016). An indicator framework for assessing ecosystem services in support of the EU Biodiversity Strategy to 2020. Ecosystem Services, 17, 14-23. 
Maes, J., Teller, A., Erhard, M., Murphy, P., Paracchini, M. L., Barredo, J. I., Grizzett, B., Cardoso, A., Somma, F., Petersen, J.-E., Meiner, A., Gelaber, E. R., Zal, N., Kristensen, P., Bastrup-Birk, A., Biala, K., Romao, C., Piroddi, C., Egoh, B., \& Fiorina, C. (2014). Mapping and assessment of ecosystems and their services: Indicators for ecosystem assessments under Action 5 of the EU Biodiversity Strategy to 2020 (2nd Report). European Commission. https://ec.europa. eu/environment/nature/knowledge/ecosystem_ assessment/pdf/2ndMAESWorkingPaper.pdf

Millennium Ecosystem Assessment. (2005). Guide to the Millennium Ecosystem Assessment reports. https:// www.millenniumassessment.org/en/index.html

Moseley, D., Marzano, M., Chetcuti, J., \& Watts, K. (2013). Green networks for people: Application of a functional approach to support the planning and management of greenspace. Landscape and Urban Planning, 116, 1-12.

Natural England. (2010). Nature nearby: Accessible natural greenspace guidance (Report No. NE265).

Nesshöver, C., Assmuth, T., Irvine, K. N., Rusch, G. M., Waylen, K. A., Delbaere, B., Haase, D., Jones-Walters, L., Keune, H., Kovacs, E., Krauze, K., Külvik, M., Rey, F., van Dijk, J., Vistad, O. I., Wilkinson, M. E., \& Wittmer, H. (2017). The science, policy and practice of naturebased solutions: An interdisciplinary perspective. Science of the Total Environment, 579, 1215-1227. https://doi.org/10.1016/j.scitotenv.2016.11.106

Norris, C., Hobson, P., \& Ibisch, P. L. (2011). Microclimate and vegetation function as indicators of forest thermodynamic efficiency. Journal of Applied Ecology, 49, 562-570.

Reed, M. S., Allen, K., Attlee, A., Dougill, A. J., Evans, K. L., Kenter, J. O., Hoy, J., McNab, D., Stead, S. M., Twyman, C., Scott, A. S., Smyth, M. A., Stringer, L. C., \& Whittingham, M. J. (2017). A place-based approach to payments for ecosystem services. Global Environmental Change, 43, 92-106. https://doi.org/ 10.1016/j.gloenvcha.2016.12.009

Schick, A., Hobson, P. R., \& Ibisch, P. L. (2017). Conservation and sustainable development in a VUCA world: The need for a systemic and ecosystem-based approach. Ecosystem Health and Sustainability, 3(4), Article e01267. https://doi.org/10.1002/ehs2.1267

Schick, A., Porembski, S., Hobson, P. R., \& Ibisch, P. L. (2019). Classification of key ecological attributes and stresses of biodiversity for ecosystem-based conservation assessments and management. Ecological Complexity, 38, 98-111. https://doi.org/10.1016/ j.ecocom.2019.04.001

Spains Hall Estate. (n.d.). Integrated water management project [PowerPoint presentation]. https://www. finchingfield-pc.gov.uk/images/docs/Integrated\%20 Water\%20Management\%20project.pdf

Stanislawski, D. (1946). The origin and spread of the gridpattern town. Geographical Review, 36(1), 105-120.

Sustainable Sites Initiative. (2015). Home. https://www. sustainablesites.org

The Economics of Ecosystems and Biodiversity. (2010). Mainstreaming the economics of nature: A synthesis of the approach, conclusions and recommendations of TEEB. http://www.teebweb.org/ wp-content/uploads/Study\%20and\%20Reports/ Reports/Synthesis\%20report/TEEB\%20Synthesis\% 20Report\%202010.pdf

The Economics of Ecosystems and Biodiversity. (2011). TEEB manual for cities: Ecosystem services in urban management. http://www.teebweb.org/wpcontent/uploads/Study\%20and\%20Reports/ Additional\%20Reports/Manual\%20for\%20Cities/ TEEB\%20Manual\%20for\%20Cities_English.pdf

Town and Country Planning Association London. (2015). Green and blue space adaptation for urban areas and eco towns (GRaBS). The European Climate Adaptation Platform Climate-ADAPT. https://climateadapt.eea.europa.eu/metadata/projects/green-andblue-space-adaptation-for-urban-areas-and-ecotowns

Tratalos, J., Fuller, R. A., Warren, P. H., Davies, R. G., \& Gaston, K. J. (2007). Urban form, biodiversity potential and ecosystem services. Landscape and Urban Planning, 83(4), 308-317. https://doi.org/10.1016/ j.landurbplan.2007.05.003

URS. (2013). Payments for ecosystem services: $A$ best practice guide. Department for Environment, Food \& Rural Affairs. https://www.cbd.int/financial/pes/ unitedkingdom-bestpractice.pdf

Windhager, S., Steiner, F., \& Heymann, D. (2010). Toward ecosystem services as a basis for design. Landscape Journal, 20(2), 107-123.

World Economic Forum. (2019). The global risks report 2019. https://www.weforum.org/reports/the-globalrisks-report-2019

World Economic Forum. (2020). The global risks report 2020. https://www.weforum.org/reports/the-globalrisks-report-2020

World Economic Forum. (2021). The global risks report 2021. https://www.weforum.org/reports/the-globalrisks-report-2021

\section{About the Authors}

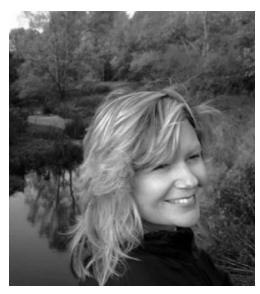

Saruhan Mosler is a senior lecturer in landscape architecture at Writtle University College. Her interest is in the urban landscape processes that lead to changes in urban morphology, place-making and urban public space production. She has focused on how our cultural everyday heritage can inform design and planning and derive place-making processes. Her recent research is on urban rivers as part of the key landscape assets in the green infrastructure systems, their role in future proof cities, and sustainable landscape development strategies. 


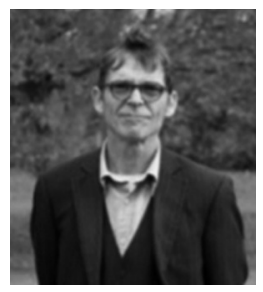

Peter Hobson is a professor in biodiversity conservation and sustainability in the School of Sustainable Environments at Writtle University College. He is also currently acting as co-director for the Centre of Econics and Ecosystem Management which is based at Eberswalde University for Sustainable Development. Apart from his academic roles, Peter is also a member of the IUCN Commission for forest ecosystems, a trustee for the UK Wilderness Foundation, board member for European Beech Forest Network, scientific adviser for European Wilderness Society, Rewilding Britain, Wild Europe, and Commissioner for Essex Climate Action Commission. His research interests include ecosystem thermodynamics and measures of ecosystem function in managed landscapes and how this research may contribute to a new paradigm of sustainable land use practice referred to as "econics." 